\title{
PENGOLAHAN AIR LIMBAH INDUSTRI KARET REMAH (CRUMB RUBBER) DENGAN MENGGUNAKAN REAGEN FENTON
}

\author{
Dian Sari Dewi ${ }^{1)}$, Heru Eko Prasetyo ${ }^{2)}$, Elfi Karnadeli ${ }^{3)}$ \\ $\left.{ }^{1}\right)$ Dosen Prodi Teknik Kimia Universitas Tamansiswa Palembang \\ 2,3) Mahasiswa Prodi Teknik Kimia- Universitas Tamansiswa Palembang \\ email : dianmuktiq@gmail.com
}

\begin{abstract}
ABSTRAK
Telah dilakukan penelitian alternatif pengolahan limbah cair industri karet yang mengandung bahan organik yang cukup tinggi, yang selama ini diolah menggunakan lumpur aktif, yaitu dengan menggunakan metode oksidasi lanjutan yang diaplikasikan dengan reagen fenton. Adapun yang menjadi parameter penelitian adalah penurunan nilai COD air limbah, dengan dua variabel penelitian yaitu variasi perbandingan molar Reagen Fenton, yaitu 1:20, 1:40, dan 1:80, dan variasi volume Reagen Fenton yaitu $5 \mathrm{ml}, 10 \mathrm{ml}, 20 \mathrm{ml}$, dan $40 \mathrm{ml}$. Dari hasil penelitian ini ternyata yang sangat efektif untuk menurunkan nilai COD dari air limbah industri karet adalah perbandingan 1:80 dengan menggunakan volume $20 \mathrm{ml}$, dan penurunan nilai COD yang dihasilkan mencapai $96,57 \%$.
\end{abstract}

Kata kunci : Air Limbah Industri Karet, COD, Reagen Fenton

\section{PENDAHULUAN}

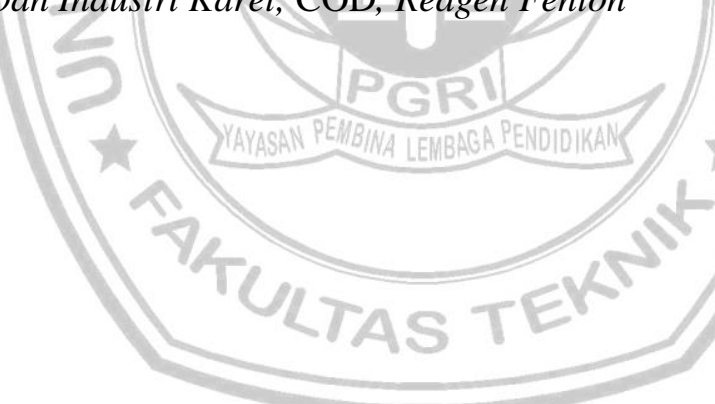

Karet alam (Havea sp.) merupakan salah satu komoditi pertanian yang penting baik untuk lingkup internasional dan teristimewa bagi Indonesia. Di Indonesia karet alam merupakan salah satu hasil pertanian terkemuka karena banyak menunjang perekonomian negara. Sebagai tanaman yang banyak dibutuhkan untuk bahan industri, karet banyak dibudidayakan sebagai tanaman perkebunan di Indonesia. Tanaman karet diusahakan mulai dari luasan kecil yang hanya ratusan meter persegi hingga mencapai luasan ribuan kilometer persegi.

Ekspor karet Indonesia umumnya dilakukan dalam bentuk karet remah atau dikenal dengan nama "Crumb Rubber" yang diklasifikasikan dengan Standar Indonesia Rubber (SIR). Produksi Crumb Rubber ada 2 (dua), yaitu High Grade adalah produksi yang berasal dari bahan baku lateks kebun (SIR 3CV, SIR 3L, SIR3WF, SIR 5), dan Low Grade adalah produksi yang berasal dari bahan baku Kempa (SIR 10, SIR 20) (Rosma Situmeang, 2014). Crumb Rubber ini diekspor langsung ke negara konsumen (Amerika, Eropa dan Asia maupun Negara ketiga). Perbandingan ekspor ke negara Amerika sebesar 60 persen sampai 75 persen, 20 persen ke Negara Jepang, dan selebihnya ke Eropa dan ke Negara Australia. Karet remah sebagian besar diproduksi oleh perusahaan swasta menggunakan bahan baku karet dalam bentuk koagulum yang dikenal dengan istilah bahan olah karet (bokar) yang dihasilkan dari tanaman karet yang dikelola rakyat. Tanaman karet yang dikelola rakyat 
memiliki luas areal tanam sekitar 64 persen dari total areal tanam karet Indonesia seluas 2,29 juta hektar.

Dalam proses pengolahan karet untuk menghasilkan produk-produk yang diinginkan, juga dihasilkan produk lain yang disebut limbah. Limbah yang menjadi masalah di pabrik-pabrik biasanya berupa cairan, yang bersumber dari proses pencucian, pencabikan, penggilingan, peremahan, pengeringan, dan pengepresan bokar. Limbah yang dihasilkan banyak mengandung bahan organik yang tinggi, sisa senyawa bahan olahan karet, senyawa karbon, nitrogen, fosfor, dan senyawa-senyawa lain seperti ammonia yang cukup tinggi (Chasri Nurhayati, dkk, 2013).

Material organik yang terdapat pada air limbah industri karet apabila berada dalam konsentrasi tinggi dan langsung dibuang tanpa pengolahan akan menimbulkan pencemaran pada lingkungan perairan sehingga terjadi penurunan kualitas air. Kondisi ini dapat menimbulkan gangguan, kerusakan dan bahaya bagi semua mahluk hidup yang bergantung pada sumber daya air tersebut. Industri karet merupakan industri yang menghasilkan limbah dengan kadar $\mathrm{NH}_{3}$ yang tinggi, yang akan mengakibatkan penurunan oksigen terlarut dalam air sehingga terjadi perubahan warna air dan timbul bau yang tidak sedap. Selama ini pengolahan limbah karet umumnya menggunakan lumpur aktif, yang menggunakan biaya yang cukup mahal. Reagen Fenton muncul sebagai alternatif pengolahan limbah ini, di mana Reagen Fenton pernah digunakan pada pengolahan limbah domestik (Elfiana, 2013) dan limbah tekstil (Tuti. E., Agustina dkk, 2011) yang ternyata dapat menurunkan angka COD dengan persentase yang cukup besar.

Berdasarkan latar belakang itulah dilakukan penelitian menggunakan reagen fenton untuk pengolahan limbah industri karet. Dari uraian latar belakang di atas diketahui bahwa air limbah industri karet mengandung bahan organik yang tinggi dan bila dibuang ke dalam air tanpa pengolahan terlebih dahulu akan menimbulkan dampak negatif berupa penurunan kualitas badan air penerima. Sehingga memunculkan hal-hal yang menjadi permasalahan pada penelitian ini, yaitu :

1. Apakah Reagen Fenton dapat menurunkan angka COD pada air limbah industri karet tersebut?

2. Apakah semakin besarnya rasio perbandingan volume Reagen Fenton maka semakin besar pula penurunan angka COD tersebut?

3. Apakah semakin banyak volume Reagen Fenton yang ditambahkan maka semakin besar pula penurunan angka COD tersebut?

Permasalahan-permasalahan tersebut di atas menjadi tujuan pada penelitian ini, yaitu :

1. Mengetahui apakah reagen Fenton dapat digunakan dalam pengolahan air limbah industri karet sehingga memenuhi standar baku mutu air limbah yang diperbolehkan dibuang ke lingkungan.

2. Mengetahui berapa besar ratio perbandingan volume Reagen Fenton yang ditambahkan terhadap penurunan angka COD air limbah industri karet .

3. Mengetahui berapa besar penurunan angka COD air limbah industri karet dengan menggunakan reagen Fenton.

Manfaat yang bisa diperoleh dari penelitian ini adalah memberikan pengetahuan dan informasi kepada masyarakat serta pelaku industri karet mengenai dampak air limbah karet tersebut, dan memberikan solusi alternatif pengolahan air limbah industri karet sehingga mengurangi beban polutan pada perairan..

\section{TINJAUAN PUSTAKA}

\section{Proses Produksi Pabrik Karet Remah}

Bahan jadi karet diolah dari getah karet dan getah karet diperoleh dengan cara mengorek (menderes) kulit batang karet sehingga getah karet dapat keluar secara perlahan-lahan dan dikumpulkan dalam suatu wadah. Kemudian getah karet dari kebun ini dicampur dengan bahan kimia 
yang berfungsi sebagai pengawet atau langsung digumpalkan dengan zat asam menjadi bahan baku untuk pembuatan bahan jadi pada suatu pabrik pengolahan karet.

Ada dua jenis karet, yaitu karet alam dan karet sintetis. Karet alam mempunyai sifat daya elastisitas dan daya lentur yang baik, plastis, tidak mudah panas, dan tidak mudah retak. Karet sintetis memiliki ketahanan terhadap minyak, oksidasi, panas, atau suhu tinggi dan kedap gas (https://id.wikipedia.org.). Karet alam banyak digunakan sebagai bahan baku dalam industri, umumnya alat-alat yang dibuat dari karet alam sangat penting bagi kehidupan sehari-hari maupun dalam usaha industri seperti mesin-mesin penggerak. Crumb rubber (karet remah) merupakan salah satu jenis produksi karet alam yang digolongkan sebagai karet spesifikasi teknis (TSR=Technical Spesified Rubber), karena penilaian mutunya tidak dilakukan secara visual, namun dengan menganalisis sifat-sifat fisika-kimianya (http://www.kdei-taipei.org). Crumb rubber adalah bahan yang $100 \%$ dibuat dari nabati alami, dimana dalam pengolahannya digunakan dua golongan bahan baku, yaitu lateks kebun dan lump atau gumpalan mutu rendah. Crumb rubber ini dapat diolah menjadi aneka ragam barang yang sangat luas penggunaannya. Karet dalam golongan ini dapat dibedakan antara yang bermutu lebih tinggi dan yang bermutu lebih rendah, atau yang diproduksi dari bahan karet lain seperti lembar tidak diasap dan lain-lain .

Berikut adalah diagram alir pembuatan karet remah skala industri :

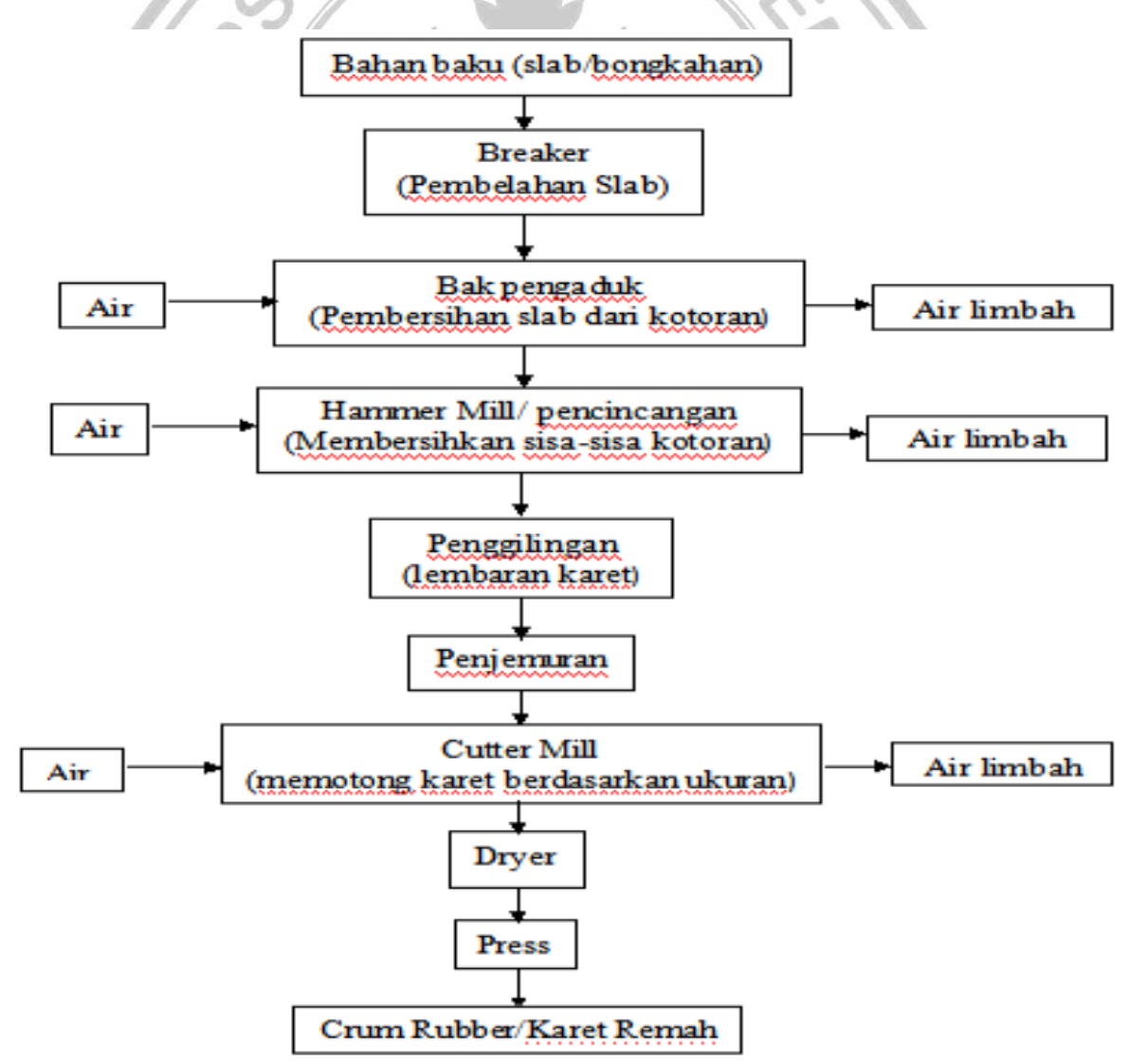

Gambar 1. Diagram alir pembuatan karet remah skala industri 


\section{Sumber Utama Air Limbah Pabrik Karet}

Sumber utama air limbah pada industri karet remah berasal dari air buangan dan pada prosesproses tertentu, seperti pada proses breaker ada bau yang dikeluarkan oleh bahan baku dan air buangan, begitu pula pada hammer mill dan proses penjemuran. Air limbah karet mengandung polutan organik yang tinggi serta padatan tersuspensi maupun terlarut yang akan mengalami perubahan fisika, kimia, dan biologi. Berikut ini adalah data-data karakteristik air limbah industri karet:

Table 1: Karakteristik Air Limbah Industri Karet

\begin{tabular}{|c|c|c|}
\hline \multirow{2}{*}{ Parameter } & \multicolumn{2}{|c|}{ Karet Remah } \\
\cline { 2 - 3 } & Kisaran & Rataan \\
\hline $\mathrm{pH}$ & $6,7-6,9$ & 6,78 \\
\hline $\mathrm{COD}(\mathrm{mg} / \mathrm{L})$ & $1352-1488$ & 1403 \\
\hline $\mathrm{BOD}(\mathrm{mg} / \mathrm{L})$ & $420-725$ & 566 \\
\hline $\mathrm{TSS}(\mathrm{mg} / \mathrm{L})$ & $1140-1320$ & 1151 \\
\hline $\mathrm{NH} 3(\mathrm{mg} / \mathrm{L})$ & $73-154$ & 83 \\
\hline
\end{tabular}

Karakteristik air limbah yang berasal dari produk karet remah dapat dilihat berdasarkan hasil rataan dari parameter yaitu pH 6,78,COD $1403 \mathrm{mg} / \mathrm{L}$, BOD $566 \mathrm{mg} / \mathrm{L}$, TSS $1151 \mathrm{mg} / \mathrm{L}, \mathrm{NH} 383 \mathrm{mg} / \mathrm{L}$ dan berdasarkan volume yang dihasilkan dari air limbah tersebut adalah $26,6 \mathrm{~m}^{3} / \mathrm{ton}$.

\section{Pengaruh Air Limbah Pabrik Karet}

Dampak yang ditimbulkan oleh pencemaran air limbah industri karet adalah gangguan terhadap kehidupan biotik yang disebabkan oleh meningkatnya kandungan bahan organik. Selama proses degradasi limbah oksigen banyak dikonsumsi, sehingga ketika polutan organik di dalam air sedikit, oksigen yang hilang dari air akan segera digantikan oleh oksigen hasil reaerasi dari udara dan oleh proses fotosintesis. Apabila konsentrasi polutan organik cukup tinggi, maka akan terjadi kondisi anaerobik (tidak ada oksigen) yang menghasilkan produk dekomposisi berupa amonia, hidrogen sulfida, karbondioksida dan metana. Air limbah juga dapat menjadi sumber pengotor, sehingga bila tidak dikelola dengan baik dapat menimbulkan pencemaran air, menimbulkan bau yang tidak sedap serta pemandangan yang tidak menyenangkan.

\section{Baku Mutu Air Limbah Pabrik Karet}

Untuk menghindari terjadinya pencemaran air di lingkungan maka ditetapkan baku mutu air limbah. Baku mutu air limbah adalah batas adalah batas kadar yang diperbolekan bagi zat atau bahan pencemar untuk dibuang dari sumber pencemaran kedalam air pada air, sehingga tidak mengakibtkan dilampauinya baku mutu air.

Tabel 2: Baku Mutu Air Limbah*)

\begin{tabular}{|c|c|c|}
\hline \multirow{2}{*}{ Parameter } & \multicolumn{2}{|c|}{ Karet Bentuk Kering } \\
\cline { 2 - 3 } & $\begin{array}{c}\text { Kadar Maksimum } \\
(\mathrm{mg} / \mathrm{L})\end{array}$ & $\begin{array}{c}\text { Beban Pencemaran } \\
(\mathrm{kg} / \mathrm{ton})\end{array}$ \\
\hline BOD & 60 & 2,4 \\
\hline COD & 200 & 8 \\
\hline Residu Tersuspensi & 100 & 4 \\
\hline Ammonia Total & 5 & 0,2 \\
\hline $\begin{array}{c}\text { Nitrogen Total } \\
\text { (sebagai } \mathrm{N})\end{array}$ & 10 & 0,4 \\
\hline
\end{tabular}

*Pergub Sumsel Nomor 8 tahun 2012 


\section{Sistem Pengolahan Air Limbah Industri Karet}

Pengolahan air limbah industri karet sampai saat sekarang kebanyakan hanya menampung air limbah kemudian didiamkan beberapa saat lalu dibuang ke perairan. Cara ini akan membutuhkan kapasitas penampungan air limbah yang besar. Terlebih lagi dikarenakan pemakaian air pada industri karet cukup besar, maka akan dihasilkan air limbah industri karet yang banyak.

Penguraian polutan air limbah karet tersebut dilakukan oleh mikroorganisme yang tidak memerlukan oksigen bebas (anaerob). Memang hal tersebut dapat berjalan walaupun memerlukan waktu yang lama. Supaya proses pengolahan dapat berjalan efektif, sehingga dibutuhkan kondisi yang paling baik bagi pertumbuhan mikroorganisme. Mikroorganisme dapat hidup pada kondisi $\mathrm{pH}$ air limbah mendekati angka netral. Air limbah industri karet bersifat asam sehingga sebelum diolah perlu dinetralkan terlebih dahulu dengan kapur agar kerja mikroorganisme berlangsung dengan baik. Mengingat waktu yang cukup panjang dalam proses pengolahan air limbah karet secara anaerob (tidak ada oksigen), maka diperlukan inovasi untuk mendapatkan proses yang singkat namun biayanya tetap murah.

Air limbah pabrik karet memiliki kandungan senyawa organik tinggi yang memiliki potensi untuk menghasilkan biogas melalui proses anaerobik. Pada umumnya, biogas mengandung 50-80\% metana, $\mathrm{CO}_{2}, \mathrm{H}_{2} \mathrm{~S}$ dan sedikit air, yang bisa dijadikan sebagai pengganti minyak tanah atau LPG. Dengan mengkonversi air limbah pabrik karet menjadi biogas, pemilik pabrik karet tidak hanya berkontribusi dalam menjaga lingkungan tetapi juga meningkatkan pendapatannya dengan mengurangi konsumsi bahan bakar pada proses pembuatan karet tersebut

Teknologi biogas dari air limbah industri karet membutuhkan area dan biaya instalasi yang mahal, sehingga banyak pemilik industry karet yang lebih memilih untuk membuat instalasi pengolahan air limbah (IPAL) yang limbahnya langsung dibuang kelingkungan. Saat ini metode yang akan diteliti adalah dengan menggunakan proses oksidasi lanjut yaitu reagen fenton sehingga diharapkan air limbah industri karet tidak berbahaya sebelum dibuang ke lingkungan.

\section{Reagen Fenton}

Reagen Fenton merupakan larutan dari hidrogen peroksida dan katalis besi yang digunakan untuk oksidasi kontaminan atau air limbah. Reagen fenton ini dapat digunakan untuk merusak komponen organik seperti trichloroethylene (TCE) dan tetrachloroethylene (PCE) (https://en.wikipedia.org). Fe(II) dioksidasi oleh hidrogen peroksida menjadi $\mathrm{Fe}(\mathrm{III})$, radikal ${ }^{\circ} \mathrm{OH}$ dan anion $\mathrm{OH}^{-}$. Pada reaksi ini keberadaan $\mathrm{Fe}(\mathrm{II})$ adalah sebagai katalis. Besi (II) sulfat merupakan jenis senyawa besi yang dipakai dalam reagen fenton.

Hidrogen peroksida merupakan oksidator kuat tetapi pada konsentrasi rendah , $0.1 \%$ kinetika reaksinya terlalu lambat untuk mendegradasi kontaminan. Sehinnga perlu penambahan Fe(II) untuk meningkatkan kekuatan oksidasi peroksida hingga dihasilkan radikal baru dan rantai reaksi dimulai. Reaksi oksidasi peroksida terkatalisis besi ini biasanya dijalankan pada $\mathrm{pH}$ 3-5 yang disebut sebagai "Fenton Chemistry" dan kombinasi reagen besi/perokisda disebut sebagai "Fenton Reagent".

Reagen fenton adalah campuran antara hidrogen peroksida dan ion besi Campuran diantara keduanya akan bergenerasi menjadi gugus radikal hidroksil mengikuti laju dari reaksi diantara keduanya (Ruppert, Bauer, Venkatadri dan Peters, 1993). Pereaksi Fenton terdiri dari oksidator hidrogen peroksida $\left(\mathrm{H}_{2} \mathrm{O}_{2}\right)$ dan katalis ion $\mathrm{Fe}^{+2}$. Reaksi Fenton menghasilkan spesi radikal hidroksil $\left({ }^{\circ} \mathrm{OH}\right)$ dan hidroperoksil $\left({ }^{\circ} \mathrm{OOH}\right)$ yang dapat memecah struktur senyawa fenolik menjadi asam-asam alifatik yang lebih ramah lingkungan bahkan mampu mendegradasi total senyawa fenolik menjadi $\mathrm{CO}_{2}$ dan $\mathrm{H}_{2} \mathrm{O}$. Reaksi fenton sekarang banyak digunkaan dalam kegiatan penanganan air limbah, tanah dan lumpur terkontaminasi dengan beberapa aplikasi sebagai berikut:

1. Destruksi polutan organik

2. Penurunan sifat racun 


\section{Peningkatan biodegradasi}

4. Penghilangan BOD/COD

5. Penghilangan warna dan bau

6. Destruksi resin pada lumpur terkontaminasi radioaktif

\section{Chemical Oxygen Demand (COD)}

COD Adalah jumlah oksigen yang dibutuhkan untuk mengoksidasi sempurna secara kimiawi senyawa organik yang terdapat air sehingga menjadi senyawa akhir anorganik.. Pengukuran dengan COD dapat digunakan untuk menentukan jumlah senyawa organic dalam suatu sampel air (Chendrika, Lusiana, 2012). COD erat kaitannya dengan BOD. Dalam bahan buangan, tidak semua bahan kimia organik dapat diuraikan oleh mikroorganisme secara cepat. Bahan organik dalam air bersifat :

1. Dapat diuraikan oleh bakteri (biodegradasi) dalam waktu lima hari

2. Bahan organik yang tidak teruraikan oleh bakteri dalam waktu lima hari

3. Bahan organik yang tidak mengalami biodegradasi

Akan tetapi tidak semua bahan organik dapat terdegradasi oleh bakteri secara biologis, sehingga untuk mendegradasi zat organik tersebut dilakukan secara kimiawi melalui proses oksidasi. Angka COD merupakan ukuran bagi pencemaran air oleh zat organik yang secara alamiah dapat dioksidasi dan mengakibatkan berkurangnya oksigen terlarut di air. Sehingga konsentrasi COD dalam air harus memenuhi standar baku mutu yang telah ditetapkan agar tidak mencemari lingkungan

\section{METODOLOGI PENELITIAN}

\section{Alat dan Bahan Penelitian}

Alat yang dibutuhkan: Gelas kimia, Erlenmeyer,Gelas ukur, Neraca analitik, Pengaduk, Pipet volumetric, $\mathrm{pH}$ meter/ kertas lakmus, Labu ukur sedangkan bahan yang dibutuhkan: Limbah Industri karet, $\mathrm{H}_{2} \mathrm{O}_{2} 30 \%, \mathrm{FeSO}_{4} 4$ mol, Aquadest

\section{Alur Pelaksanaan Penelitian}

Pelaksanaan penelitian ini terdiri dari berbagai ruang lingkup pekerjaan yang diawali dengan analisa awal sampel dan penambahan reagen fenton

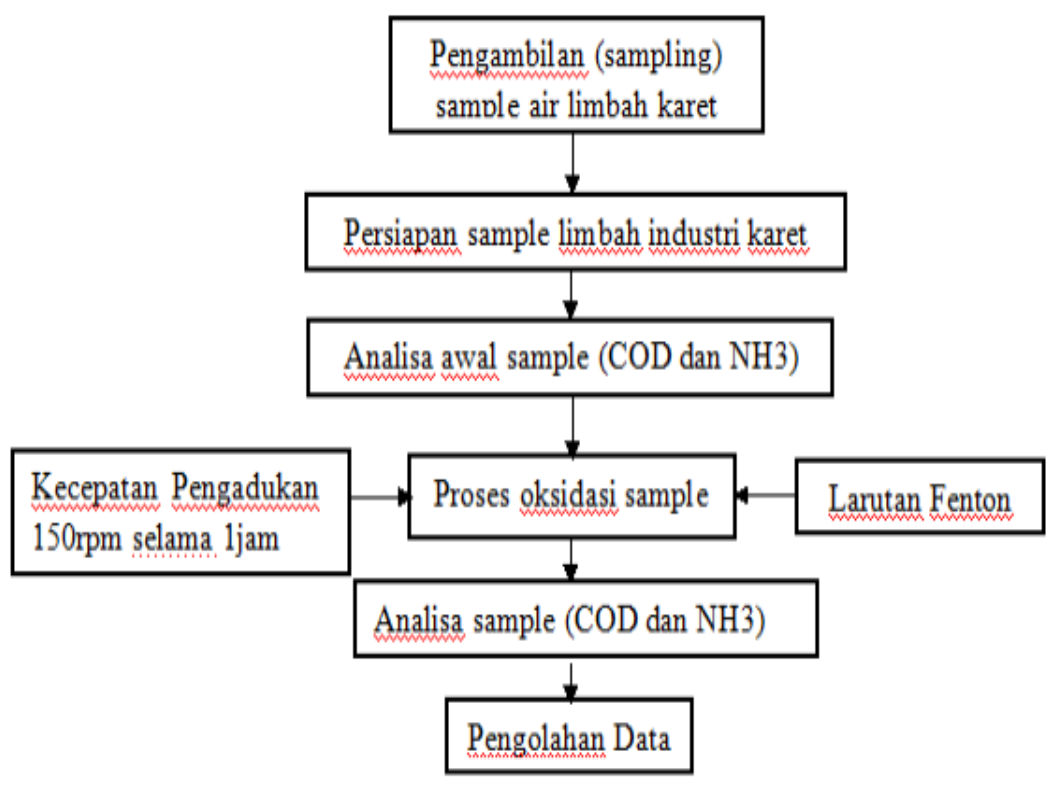

Gambar 2. Diagram Alur Penelitian 


\section{Metode Penelitian}

Penelitian ini dilakukan dalam 3 tahap, yaitu :

a. Tahap Pertama

Tahap pertama adalah pengambilan sampel air limbah industri karet, keadaan limbah haruslah original dari mulai pengambilan sample hingga penelitian dilakukan terhadap sampel. Sampel air limbah diambil langsung dari sisa pengolahan industri karet. Lokasi pengambilan sample berada di kecamatan Seberang Ulu Palembang.

b. Tahap Kedua

Tahap kedua adalah penentuan variabel penelitian dan pembuatan Reagen Fenton.

- Penentuan variabel penelitian variasi perbandingan molar Reagen Fenton,yaitu :

1) $\mathrm{FeSO}_{4} .7 \mathrm{H}_{2} \mathrm{O}: \mathrm{H}_{2} \mathrm{O}_{2}=1: 20$

2) $\mathrm{FeSO}_{4} .7 \mathrm{H}_{2} \mathrm{O}: \mathrm{H}_{2} \mathrm{O}_{2}=1: 40$

3) $\mathrm{FeSO}_{4} .7 \mathrm{H}_{2} \mathrm{O}: \mathrm{H}_{2} \mathrm{O}_{2}=1: 80$

- Pembuatan Reagen Fenton

a) $\mathrm{FeSO}_{4} \cdot 7 \mathrm{H}_{2} \mathrm{O}: \mathrm{H}_{2} \mathrm{O}_{2}(1: 20)$

$$
\begin{array}{ll}
\mathrm{FeSO}_{4} .7 \mathrm{H}_{2} \mathrm{O} & =4 \mathrm{mM} \\
\mathrm{H}_{2} \mathrm{O}_{2} & =80 \mathrm{mM}
\end{array}
$$

b) $\mathrm{FeSO}_{4} \cdot 7 \mathrm{H}_{2} \mathrm{O}: \mathrm{H}_{2} \mathrm{O}_{2}(1: 40)$

$$
\mathrm{FeSO}_{4} .7 \mathrm{H}_{2} \mathrm{O}=4 \mathrm{mM}
$$$$
\mathrm{H}_{2} \mathrm{O}_{2} \quad=160 \mathrm{mM}
$$

c) $\mathrm{FeSO}_{4} \cdot 7 \mathrm{H}_{2} \mathrm{O}: \mathrm{H}_{2} \mathrm{O}_{2}(1: 80)$

$$
\begin{array}{ll}
\mathrm{FeSO}_{4} .7 \mathrm{H}_{2} \mathrm{O} & =4 \mathrm{mM} \\
\mathrm{H}_{2} \mathrm{O}_{2} & =320 \mathrm{mM}
\end{array}
$$

c. Tahap Ketiga

Tahap ketiga adalah menentukan konsentrasi awal limbah yang akan diuji. Sebelum melakukan analisa dengan menggunakan reagen Fenton, terlebih dahulu kita harus melakukan pengujian untuk mengetahui konsentrasi awal dari air limbah industri karet. Berikut konsentrasi awal dari air limbah industri karet tersebut :

- $\mathrm{pH} 3.7$

- $\quad$ COD $5738 \mathrm{mg} / \mathrm{L}$

\section{Prosedur Penelitian}

Penelitian secara teknis dilakukan jika telah mendapatkan nilai optimum parameter yang akan diuji dari sample industri karet tersebut.

Adapun prosedur percobaan adalah :

1. Masukkan air limbah karet sebanyak $250 \mathrm{ml}$ kedalam erlenmeyer.

2. Tambahkan katalis $\mathrm{FeSO}_{4} .7 \mathrm{H}_{2} \mathrm{O}$ sebanyak $5 \mathrm{ml}$ dengan konsentrasi $4 \mathrm{mM}$ dan aduk dengan kecepatan $150 \mathrm{rpm}$ selama $1 \mathrm{jam}$.

3. Tambahkan $\mathrm{H}_{2} \mathrm{O}_{2}$ sebanyak $5 \mathrm{ml}$ dengan konsentrasi $80 \mathrm{mM}$

4. Lakukan analisa secepatnya untuk parameter COD.

5. Ulangi percobaan untuk $\mathrm{FeS}_{\mathrm{O} 4 .} \cdot 7_{\mathrm{H} 2} \mathrm{O}: \mathrm{H}_{2} \mathrm{O} 2$ dengan rasio molar $1: 40$ dan $1: 80$.

6. Ulangi percobaan untuk rasio molar yang terbaik dengan penambahan volume $10 \mathrm{ml}, 20 \mathrm{ml}$, dan $40 \mathrm{ml}$.

Kemudian lakukan analisa COD sesuai dengan metode yang dipakai di Laboratorium Lingkungan Badan Lingkungan Hidup Provinsi Sumatera Selatan. 


\section{Prosedur Analisa COD (Chemical Oxygen Demand )}

Alat dan Bahan :Tabung reaksi, COD reaktor, pipet volume, spektrofotometer UV, contoh uji, larutan pencerna $\left(\mathrm{K}_{2} \mathrm{Cr}_{2} \mathrm{O}_{7}, \mathrm{H}_{2} \mathrm{SO}_{4}, \mathrm{HgSO}_{4}\right.$, air suling), larutan pereaksi $\left(\mathrm{AgSO}_{4}, \mathrm{H}_{2} \mathrm{SO}_{4}\right.$ pekat $)$.

Prosedur Analisa : Pipet contoh uji 2,5 ml masukkan kedalam tabung reaksi (kultur).Tambahkan larutan pencerna 1,5 $\mathrm{ml}$ dan larutan pereaksi 3,5 ml. Tutup dan aduk secara perlahan dan sekali-kali dibuka kemudian ditutup rapat. Masukkan contoh uji ke COD reaktor lalu panaskan selama 2 jam dengan temperatur $150^{\circ} \mathrm{C}$. Setelah 2 jam angkat dan biarkan dingin contoh uji, setelah dingin baca contoh uji ke spektrofotometer dengan panjang gelombang $600 \mathrm{~nm}$. Kemudian catat hasil pembacaan.

\section{HASIL DAN PEMBAHASAN}

Data Hasil Pengolahan air limbah industri karet dengan menggunakan Reagen Fenton dilakukan dengan dua variabel. Variabel pertama yaitu variasi perbandingan molar Reagen Fenton dan variabel kedua yaitu variasi volume Reagen Fenton. Parameter yang diamati pada penelitian ini ialah COD.

Hasil analisa awal sampel air limbah industri karet didapat nilai pH 3,7 dan COD 5738 $\mathrm{mg} / \mathrm{L}$, dan hasil analisa akhir sampel air limbah industri karet setelah proses oksidasi yang disajikan ke dalam tabel berikut :.

Table 3: Hasil COD (mg/L) dengan Perbandingan Rasio Reagen Fenton

\begin{tabular}{|c|c|c|c|}
\hline \multirow{2}{*}{$\begin{array}{c}\text { Volume } \\
\text { Reagen } \\
\text { Fenton (ml) }\end{array}$} & \multicolumn{3}{|c|}{ Rasio Molar Reagen fenton } \\
\cline { 2 - 4 } & $1: 20$ & $1: 40$ & $1: 80$ \\
\hline 5 & 342,545 & P & 322,597 \\
\hline 5 & 342,251 & 245,137 \\
\hline Rata-rata & 342,398 & 322,345 & $\mathbf{2 4 5 , 1 7 1}$ \\
\hline
\end{tabular}

Table 4: Hasil COD (mg/L) dengan Perbandingan Volume

\begin{tabular}{|c|c|c|c|}
\hline \multirow{2}{*}{$\begin{array}{c}\text { Volume Reagen } \\
\text { Fenton }(\mathrm{ml})\end{array}$} & \multicolumn{3}{|c|}{ Rasio Molar Reagen Fenton 1:80 } \\
\cline { 2 - 4 } & Simplo & Duplo & Rata-Rata \\
\hline 5 & 245,137 & 245,105 & 245,171 \\
\hline 10 & 218,286 & 218,057 & 218,171 \\
\hline 20 & 197,017 & 197,162 & $\mathbf{1 9 7 , 0 9 4}$ \\
\hline 40 & 208,542 & 208,580 & 208,561 \\
\hline
\end{tabular}

\section{Pembahasan Hasil Penelitian}

\section{Perbandingan Molar reagen Fenton Terhadap Nilai COD.}

Pada analisa pertama yaitu dengan menggunakan variasi molar Reagen Fenton 1:20, 1:40 dan 1 :80. Volume Reagen Venton yang digunakan sebesar $5 \mathrm{ml}$. Nilai COD yang didapat ditunjukkan pada gambar 3 dibawah. 


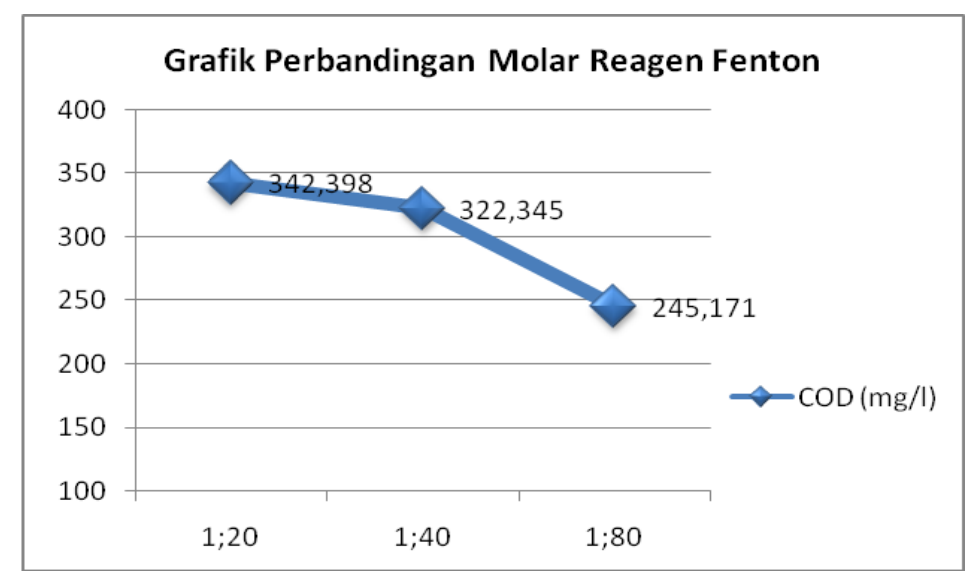

Gambar 3. Grafik Perbandingan Molar Reagen Fenton Terhadap Nilai COD

Dari Grafik diatas dapat dilihat bahwa terjadi penurunan angka COD dari air limbah industri karet yang sangat signifikan, dimana rasio Molar Ragen Fenton 1: 80 mempunyai angka penurunan COD terbaik yaitu 245, $171 \mathrm{mg} / \mathrm{L}$. Nilai COD ini jauh dari analisa sampel awal sebesar $5738 \mathrm{mg} / \mathrm{L}$ namun masih diatas baku mutu lingkungan untuk limbah buangan industry karet yang diatur oleh pemerintah, yakni maksimal $200 \mathrm{mg} / \mathrm{L}$, oleh karena itu dilakukan analisa lanjtan dengan dengan menggunakan variasi volume pada penurunan persentase nilai COD terbesar yaitu pada perbandingan molar reagen fenton $1: 80$.

\section{Volume Reagen Fenton terhadap Nilai COD}

Analisa lanjutan yaitu dengan menggunakan variasi volume sebesar $5 \mathrm{ml}, 10 \mathrm{ml}, 20 \mathrm{ml}$ dan 40, dimana perbandingan molar Reagen Fenton yang digunakan adalah 1:80. Nilai COD yang didapat ditunjukkan pada gambar 4 dibawah.

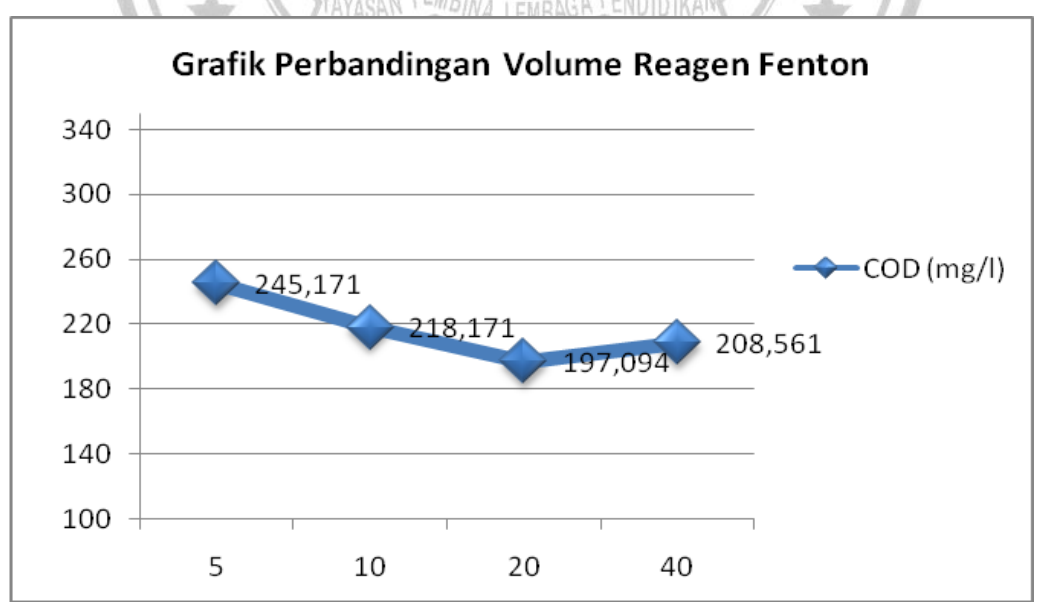

Gambar 4. Grafik Perbandingan Volume Reagen Fenton terhadap Nilai COD

Dari gambar 4 dapat dilihat bahwa dengan penambahan volume Reagen Fenton maka terjadi penurunan angka COD yang cukup significant, Pada penambahan volume $40 \mathrm{~mL}$ terjadi kenaikan kembali nilai COD karena reaksi pemecahan kandungan organik oleh ion-ion hidroksil yang berasal dari $\mathrm{H}_{2} \mathrm{O}_{2}$ menjadi mineral-mineral yang mengendap sudah tidak sempurna lagi bahkan cenderung jenuh yaitu menjadi 208,561 mg/L. Sehingga didapat angka penurunan COD maksimum yaitu pada volume $20 \mathrm{ml}$ sebesar 197,094 mg/l dimana persen degradasi COD sebesar 96,565\%. angka ini sudah mencapai standar mutu COD yang diperbolehkan dibuang ke lingkungan. 


\section{Menghitung Persen Degradasi COD}

$$
\% \text { Degradasi COD }=\frac{\operatorname{COD}_{0}-\operatorname{COD}_{\mathrm{t}}}{\mathrm{COD}_{0}} \times 100 \%
$$

Dimana $\mathrm{COD}_{0}$ merupakan nilai COD yang didapat pada sampel limbah awal, dan $\mathrm{COD}_{\mathrm{t}}$ merupakan nilai COD setelah pengolahan (selama 1 jam) dengan kondisi tertentu.

Diketahui:

$$
\begin{aligned}
& \operatorname{COD}_{0}=5738 \mathrm{mg} / \mathrm{L} \\
& \operatorname{COD}_{\mathrm{t}}=197,094 \mathrm{mg} / \mathrm{L}
\end{aligned}
$$
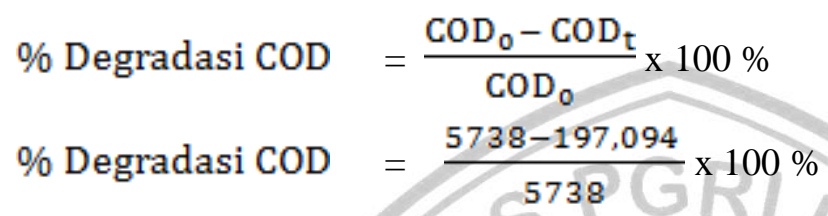

$$
=96,57 \%
$$

\section{KESIMPULAN}

Adapun kesimpulan yang dapat diambil dari penelitian ini :

1. Reagen fenton dapat digunakan sebagai alternatif untuk menurunkan angka COD pada pengolahan air limbah industri karet, sebelum dibuang ke lingkungan.

2. Rasio perbandingan molar Reagen Fenton dalam menurunkan angka COD air limbah industri karet didapat nilai terbaik pada perbandingan $1: 80$ yaitu dengan nilai penurunan COD sebesar $245,171 \mathrm{mg} / \mathrm{l}$.

3. Volume penambahan Reagen Fenton maksimum terhadap penurunan nilai COD air limbah industri karet adalah $20 \mathrm{mg} / \mathrm{l}$ atau sebesar $96,57 \%$.

\section{SARAN}

Nilai COD dapat diturunkan dengan menggunakan variasi perbandingan molar dan volume Reagen Fenton, sehingga dapat disarankan untuk penelitian lanjutan dengan menggunakan variasi waktu pengadukan dan kecepatan pengadukan.

\section{DAFTAR PUSTAKA}

Chendrika, Lusiana. Advanced Oxidation Process for Textile wastewater.http://lusianachendrika.blogspot.com/2012/07/padaanalisis-limbah-seringkita.html.

Elfiana. 2013. Penurunan Konsentrasi COD Air Limbah Domestik dengan Reagen Fenton Secara Batch. Lhoksumawe.

Fenton's Reagent. https://en.wikipedia.org/wiki/Fenton\%27s_reagent

Jenis-jenis Karet. https://id.wikipedia.org/wiki/Jenis_karet. 
Keputusan Menteri Lingkungan Hidup No.Kep-51/MENLH/10/1995 tentang Baku Mutu Limbah Cair Bagi Kegiatan Industri.

Nurhayati., C., dkk., 2013, Optimasi Pengolahan Limbah Cair Karet Remah Menggunakan Mikroalga Indigen dalam Menurunkan Kadar BOD, COD, TSS”.

Peraturan Gubernur Sumatera Selatan Nomor 8 Tahun 2012 tentang Baku Mutu Air Limbah

Ruppert G., Bauer R. 1993. Mineralization of cyclic organic water contaminants by the photo-Fenton reaction: influence of structure and substituents. Chemosphere, 27, 1339-1347.

Situmeang, Rosma. Proses Pengolahan Karet, 2014.

http://www.slideshare.net/RosmaSitumeang/proses-pengolahan-karet.

Tuti. E. Agustina, dkk., 2011, Pengolahan Air Limbah Pewarna Sintetis dengan Menggunakan Reagen Fenton", Prosiding Seminar Nasional AVoER ke-3.

Upaya Industry karet Nasional dalam Menghadapi Persaingan Pasar internasional. http://www.kdeitaipei.org/banner/karet.htm

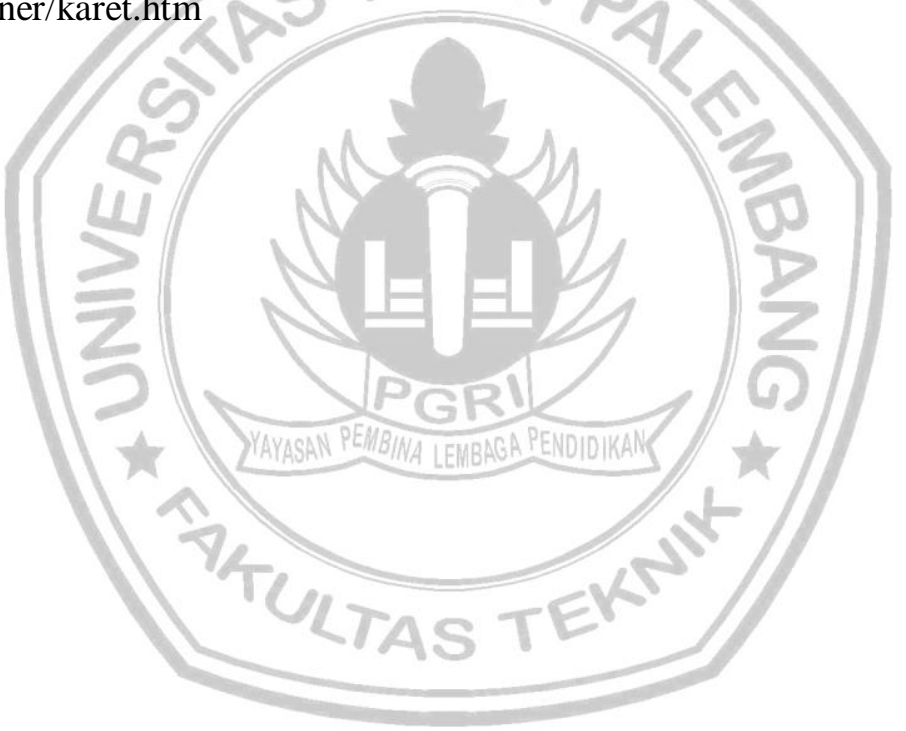

